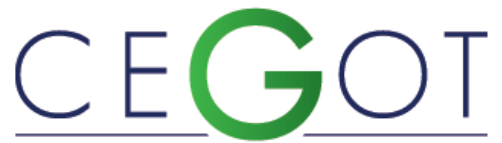

Centro de Estudos de Geografia e Ordenamento do Território
Neves, Gustavo

Universidade de São Paulo, Escola de Engenharia de São Carlos, Programa de Pós-Graduação em Ciências da

Engenharia Ambiental

13566-590 - São Carlos-SP, Brasil. Av. Trabalhador Sãocarlense, 400 qustavozen@usp.br

GaLlaRDo, NúRIA

Universidade de São Paulo, Escola de Engenharia de São

Carlos, Programa de Pós-Graduação em Ciências da

Engenharia Ambiental

13566-590 - São Carlos-SP, Brasil. Av. Trabalhador Sãocarlense, 400

nuriapg@sc.usp.br

\section{FeLíCIO, RICARDO}

Universidade de São Paulo, Faculdade de Filosofia, Ciências e

Letras Humanas, Departamento de Geografia

05508-080 - São Paulo-SP. Brasil. Avenida Prof. Lineu Prestes, 338. Cidade

Universitária

ricaftnt@yandex.com

MACEDO, SILVIO

Universidade de São Paulo, Faculdade de Arquitetura e

Urbanismo, Departamento de Projeto

03178-200 - São Paulo (SP) Brasil. Rua do Lago, 876 - Butantã

ssmduck@usp.br

VecCHIa, Francisco

Universidade de São Paulo, Escola de Engenharia de São

Carlos, Programa de Pós-Graduação em Ciências da

Engenharia Ambiental

13566-590 - São Carlos-SP, Brasil. Av. Trabalhador Sãocarlense, 400

fvecchia@sc.usp.br

\title{
Variação da temperatura de superfície em diferentes usos do solo na cidade de São Carlos-SP
}

\section{Variation of surface temperature in different land uses in the city of São Carlos-SP}

Referência: Neves, Gustavo et al. (2018). Variação da temperatura de superfície em diferentes usos do solo na cidade de São Carlos-SP. Revista de Geografia e Ordenamento do Território (GOT), n. ${ }^{\circ} 13$ (junho). Centro de Estudos de Geografia e Ordenamento do Território, p. 315-336, dx.doi.org/10.17127/got/2018.13.014

\section{RESUMO}

O balanço de energia e o fluxo radiativo produzidos nas superfícies urbanas são objetos de poucos estudos no Brasil. O objetivo deste trabalho foi verificar a variação da temperatura superficial aparente em diferentes bairros na cidade de São Carlos-SP. A metodologia fundamenta-se na utilização de um termômetro digital infravermelho fixado em um tripé, com a aferição de pontos cardeais e colaterais nas angulações de 10ㅇ, 0ㅇ, em diversas classificações do uso do solo urbano definidas pelo Laboratório Quadro do Paisagismo do Brasil - QUAPÁ. Os resultados apontam que as temperaturas mais elevadas foram registradas para a angulação -10 - altura aproximada ao nível do pedestre. 
Palavras-chave: clima urbano, micro clima, canyon urbano, espaços livres.

\section{ABSTRACT}

The energy balance and the radioactive flux produced in urban areas are not well-studied subjects in Brazil. The objective of the present study was to verify the apparent surface temperature variation in different neighborhoods in the city of São Carlos-SP. The methodology was based on the use of an infrared digital thermometer fixed on a tripod, with manual measurement of cardinal and collateral points at angles of $10 \%$ and $0^{\circ}$, using various classifications of urban land use as defined by the Quadro do Paisagismo do Brasil (Brazilian Landscaping Framework) laboratory - QUAPÁ. The results show that the highest temperatures were recorded at the $-10^{\circ}$ angle, the relative height level of pedestrians.

Keywords: urban climate, micro climate, urban canyon, open spaces.

\section{Introdução}

A formação de condições climáticas intra-urbanas, derivadas da heterogeneidade do tecido urbano e sua estrutura morfológica, carece de estudos do clima das cidades brasileiras. 0 conhecimento mais detalhado do seu comportamento torna possível identificar os fatores causadores da diferenciação climática (MONTEIRO, C. e MENDONÇA, F., 2003, p. 96) e a interação com os indivíduos que nela vivem.

Para um indivíduo que se desloca pelos espaços livres de uma cidade, há um fluxo radiativo emitido pelas superfícies incidindo sobre ele. Este fluxo deve ser sentido principalmente pelos indivíduos cujos corpos ainda não atingiram o equilíbrio térmico com o meio urbano (MACHADO, A., 2009, p. 130), que é composto por uma variedade de materiais, como o concreto, rocha, asfalto, placas metálicas, tijolos e da própria população em vias de grande circulação cuja amplitude térmica é maior na base das estruturas (paredes, ruas e calçadas).

Por estes fatores não terem sido objetos de muitos estudos, principalmente no Brasil, onde a literatura sobre o tema é escassa, é justamente no cenário urbano em uma cidade de porte médio, de clima tropical de altitude, foi desenvolvido o trabalho experimental da observação direta destes fluxos, na escala microclimática, abaixo da canopy-layer urbano. Isso permitirá uma nova perspectiva pela qual o balanço energético pode ser experimentado do ponto de vista terrestre e não apenas extraterreno bastante difundido pela utilização de imagens e sensores de satélite. A observação direta dos fluxos pode ser 
mais reveladora do que a observação do dado aéreo, cuja natureza homogeneizadora pode esconder a essência dos fenômenos que aí se estabelecem (MACHADO, A., 2009, p. 15).

Para uma avaliação mais acurada, é possível analisar o fato climático por meio dos episódios representativos ou períodos de observação dos tipos de tempo, ou seja, a intensidade e a duração de cada massa de ar que predomina sobre um determinado lugar, relacionada aos fenômenos de circulação atmosférica. As consequências do avanço de uma frente fria sobre uma determinada localidade revela as características peculiares de cada época do ano analisada (outono, inverno e etc.).

Entretanto, há poucos trabalhos experimentais voltados à observação da variação superficial da temperatura e do fluxo radiativo nos espaços livres (MACHADO, A. e AZEVEDO, T., 2006; MACHADO, A., 2011; ALVES, E. e VECCHIA, F., 2012; MACHADO, A. e AZEVEDO, T., 2013; NEVES, G. FELÍCIO, R. e MACEDO, S., 2015) que são um dos principais elementos da estrutura urbana. É onde a sociedade faz seu uso cotidiano na forma de mobilidade, circulação, parcelamento e propriedade da terra urbana.

O objetivo geral deste trabalho é verificar as variações da temperatura superficial aparente de elementos urbanos, por meio de termômetros infravermelho, em quatro tipologias urbanas em uma cidade na faixa Tropical do Hemisfério Sul, em um período de observação representativo de inverno.

\subsection{A forma urbana e os sistemas de espaços livres}

A configuração básica da cidade é dada por elementos do espaço urbano como ruas, calçadas, lotes, edifícios, os espaços livres de edificações, todos com diferentes usos. Entende-se que os espaços livres são tidos como lugares de acessos às edificações, circulação de pedestres, de veículos e transportes terrestres e de outros usos (LEME, I., 2001, p. 2). O Espaço Livre é todo espaço não ocupado por um volume edificado (espaçosolo, espaço-água, espaço-luz) ao redor das edificações e que as pessoas têm acesso (MAGNOLI, M., 1982).

O sistema de espaços livres (SEL) é o conjunto e as relações de todos os espaços livres existentes, independente de sua dimensão, qualificação estética e funcional e de sua 
localização, sejam públicos e privados (MACEDO, S., 2010, p. 14). Os espaços livres públicos constituem-se de todos aqueles de propriedade pública, com diferentes graus de acessibilidade e apropriação. Os espaços livres privados são aqueles inseridos em áreas particulares cujo acesso não é possibilitado ao público.

Tanto os espaços livres públicos quanto os privados, formam um subsistema dentro do sistema de espaços livres e podem ser categorizados em três grupos: de caráter ambiental (áreas especialmente protegidas); de práticas sociais (circulação de pedestres e infraestrutura urbana) e espaços particulares (acesso privado e uso coletivo em ocasiões especiais) (MACEDO, S., 2012, p. 149, 150).

O espaço livre é inerente à forma urbana. Ela é derivada do crescimento em extensão da população e a implantação de modelos urbanísticos como os loteamentos fechados, parques industriais e outros. A forma da cidade brasileira está ligada ao processo de produção, aos padrões culturais, sociais e as características biofísicas e climáticas (MACEDO, S., 2010, p. 9) e não possui uma forma padronizada, apesar de apresentar características comuns. Fato este, constatado pela mancha urbana e da inserção desta no suporte físico em diferentes paisagens.

As manchas urbanas podem ser classificadas como (MACEDO, S., 2012, p. 10):

1. Lineares: encontradas em meio a vales incrustados em meio às serras e terrenos de alta declividade, orlas marinhas e fluviais e ainda ao longo de estradas. Neste caso os espaços livres do entorno são de fácil acesso ou visualização;

2. Compactas: cidades que podem ter sua origem em qualquer das outras formas listadas, que com o crescimento vão assumindo forma compacta e continua. No caso é mais necessária a existência de espaços livres para recreação dentro da mancha urbana;

3. Tentaculares: estruturadas por um núcleo central, compacto do qual irradiam braços de urbanização ao longo de eixos viários ou corpos d’água;

4. Mistas: estruturas que congregam dois ou mais tipos listados.

Cada mancha urbana contém um conjunto de tecidos urbanos e um sistema de espaços livres particular, que guarda entre si características similares devido as suas condições de formação e padrões culturais, urbanísticos, paisagísticos e econômicos (Figura 1). 

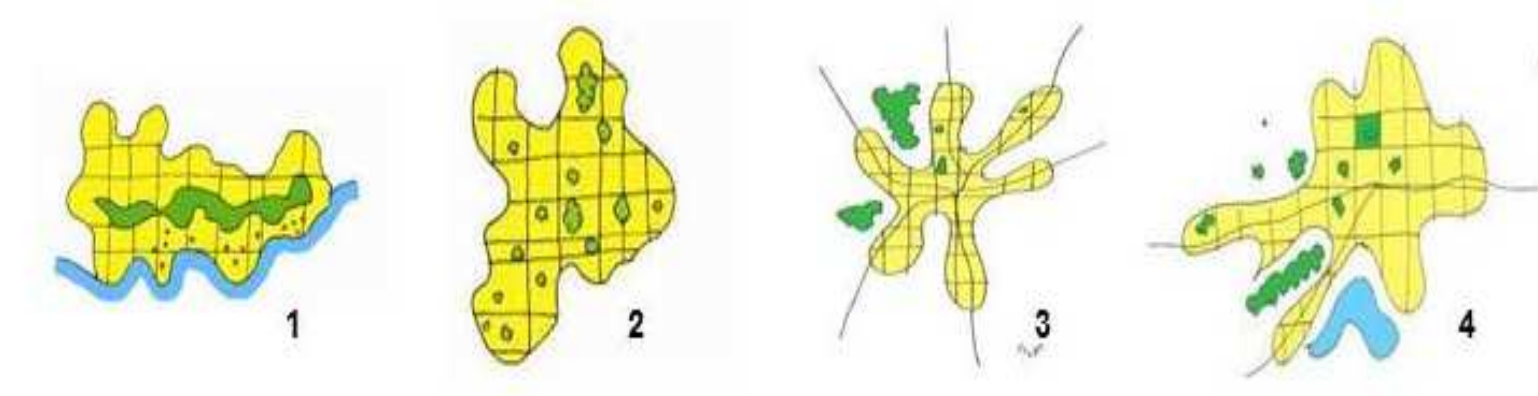

Figura 1 - Simplificações das formas urbanas (classificadas de 1 a 4). Fonte: MACEDO, S., 2013, p. 16.

As figuras acima mostram os elementos constantes nos sistemas, sendo os diversos tecidos urbanos por quadriculas que representam o sistema viário, e são ainda recortadas por manchas que representam vegetação de porte e/ou parques e praças ou corpos d'água. Naturalmente tais esquemas são simplificações, mas representam as possibilidades estruturais em que se pode apresentar a forma urbana de uma determinada cidade no contexto brasileiro.

\subsection{Mapas do Quadro do Paisagismo no Brasil}

Desde 2012, o projeto interdisciplinar intitulado "Os sistemas de espaços livres na constituição da forma urbana no Brasil: produção e apropriação" (Quadro do Paisagismo no Brasil- Sistemas de Espaços Lives - QUAPÁ-SEL II), coordenado pelo Laboratório LAB-QUAPÁ da Faculdade de Arquitetura e Urbanismo da Universidade de São Paulo, investiga as relações entre sistemas de espaços livres e a forma urbana brasileira, considerando sua produção a partir dos processos socioeconômicos e ambientais, seus aspectos comuns e especificidades locais. Dentre seus objetivos está a construção de referencial metodológico para a análise qualitativa destas relações (CAMPOS, A., et al, 2013, p. 2; MACEDO, S., 2010a; MACEDO, S., 2010b; MACEDO, S., 2013). Justamente tendo em mãos este tipo de divisão classificatória das tipologias urbanas brasileiras, foi possível criar um ensaio das zonas climáticas urbanas, sugeridas em (STEWART, I. e OKE, T., 2012) para a cidade de São Carlos, tendo em vista que a mudança para o padrão verificado para São Paulo, são bastante semelhantes, expondo assim, sua enorme importância descritiva. 
A unidade para análise e classificação por tipo predominante são as quadras, realizada por meio da foto-interpretação, apoiada em ortofotos e nas imagens do Google Earth com suas imagens aéreas e a ferramenta Google Street View que permite uma visualização acurada sobre os aspectos morfológicos e de volumetria construída a esclarecer possíveis dúvidas por parte do elaborador do mapa.

De acordo com a quantidade de espaço livre disponível é feita a classificação de quadra por quadra, o que resulta em um estudo tipo-morfológico considerando o espaço livre de edificação por quadra e verticalização por quadra.

A análise considera três faixas de porcentagem por existência de espaços livres em relação à área ocupada na quadra: (A) até 30\% da área da quadra, de ocupação mais consolidada; (B) de $30 \%$ a $50 \%$ da área da quadra com até metade de sua extensão com espaços livres; (C) mais de $50 \%$ da área da quadra livre de edificações (Figura 2).
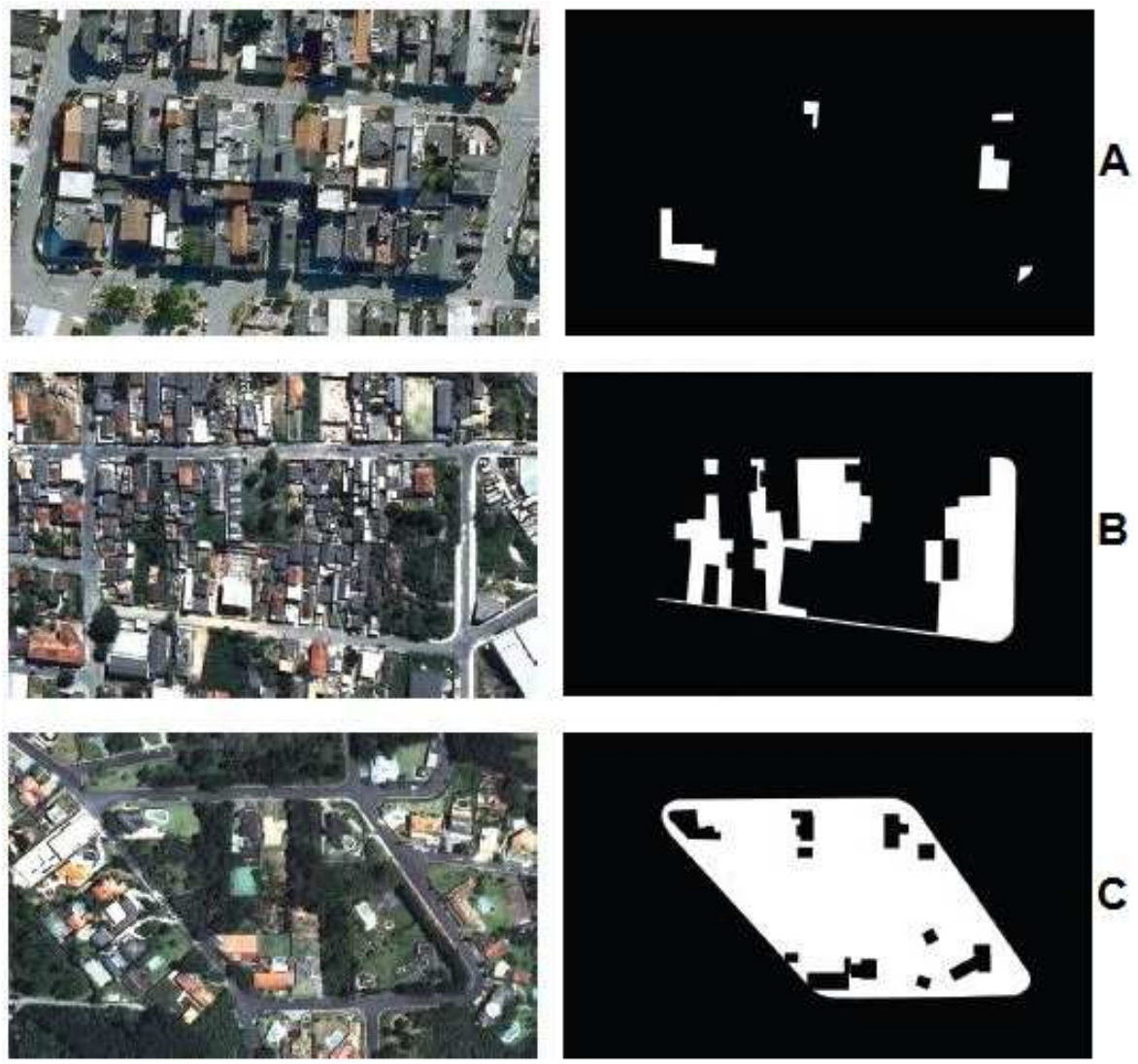

Figura 2: Exemplos de quadras entre $30 \%$ e mais de $50 \%$ de espaços livres, na Região Metropolitana de São Paulo. À direita, as partes em branco representam o espaço livre existente na quadra esquerda. Fonte: Macedo, S., 2010, p. 99. Elaboração: Gabriel Seki Kioshima. 
A investigação entre os sistemas de espaços livres são apresentados em forma de mapas e estão divididos em três grupos principais segundo o parcelamento das quadras, mencionados a seguir: O parcelamento tradicional, com a quadra subdividida em diversos lotes; O parcelamento não tradicional onde a quadra apresenta poucos lotes de grandes dimensões; Encrave constituindo porção do território, descontinuidades com relação ao tecido e malha viária do entorno, baixa conectividade e sem acessibilidade.

Para os autores, esta configuração observada e representada nos mapeamentos colabora de imediato na percepção e entendimento dos impactos relacionados à permeabilidade do solo, condições básicas de insolação e ventilação, possibilidade de arborização e outros itens que podem ser aferidos como as condições microclimáticas e as variações da temperatura superficial aparente, possibilitando estabelecer uma avaliação qualitativa do estado atual do sistema de espaços livres (CAMPOS, A., et al, 2013, p. 9).

\subsection{São Carlos: Expansão urbana e aspectos físicos}

O processo de expansão e desenvolvimento da cidade está intimamente ligado aos ciclos econômicos do interior paulista e também brasileiro, identificados em três períodos: o período do café, que foi de 1857 até 1929; da consolidação industrial, de 1930 a 1959 e o período da expansão urbana descontínua, de 1960 a 1977.

A cidade se desenvolve no contexto da expansão cafeeira no interior do Estado de São Paulo, no século XIX, sobretudo pela instalação do modal ferroviário até o porto de Santos. Tal fato originou grande fluxo migratório para o município com o crescimento urbano (FABBRO NETO, F., 2004, p. 65).

O primeiro período iniciou-se com o traçado do primeiro eixo viário e com e os arruamentos implantados em função do eixo. O padrão urbano característico desse período foi o traçado ortogonal e homogêneo, durante o século XIX (LIMA, R., 2007, p. 11 e 12). O miolo das quadras era composto por espaços livres formados pelas áreas não edificadas no fundo dos lotes (Figura 3). 


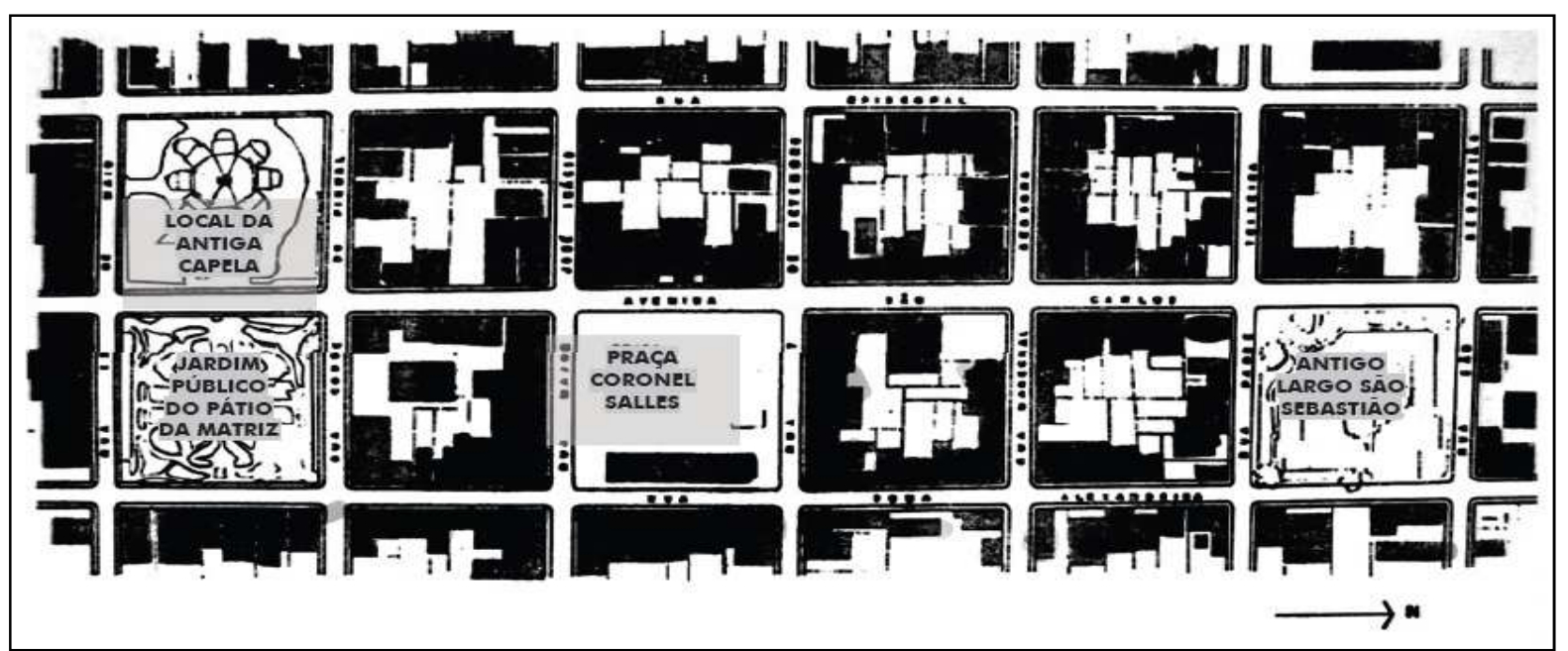

Figura 3: Planta do centro de São Carlos e o padrão de ocupação dos lotes e quadras no século XIX. Fonte: Marques, E., 1985, p. 206.

No período de 1930 a 1959, a cidade de São Carlos consolida sua economia industrial com o surgimento do setor mecânico e elétrico, motivado pela instalação da Escola de Engenharia de São Carlos na região Centro-Norte da cidade. O terceiro período, de 1960 a 1977, a industrialização cresceu em todo o Estado de São Paulo, sobretudo em São Carlos, com a implantação do Programa de Cidades Médias pelo Governo Federal e a criação da Universidade Federal de São Carlos, no final da década de 1960 (FABBRO NETO, F., 2004, p. 65; LIMA, E., 2007, p. 13, 14).

O mercado imobiliário se tornou cada vez mais especulativo e a segregação urbana foi crescente. Entre 1962 e 1977 foram criados dois Planos Diretores e um conjunto de Leis Urbanísticas (Lei Federal 6.766/79). Em 1977, a nova lei de perímetro urbano abriu precedência para uma ocupação cada vez mais extensiva e segregada da área urbana de São Carlos. Até 1950 a população era de 50.000 habitantes, aproximadamente. Em menos de 20 anos o crescimento foi de 75\%, registrando mais de 85.000 habitantes, em 1970.

Em 2001, com a intenção de adequar-se ao Estatuto das Cidades, a Prefeitura Municipal de São Carlos elaborou o Plano Diretor Municipal voltado para o zoneamento, plano físico territorial e áreas de especial interesse. Nos anos seguintes de 2002, 2004 e 2005, várias audiências públicas foram realizadas para aprofundar o debate sobre os diferentes aspectos do Plano Diretor, como Urbanização, Transporte e Habitação (DEVESCOVI, R., 1985, p. 197; 
DOZENA, A., 2001, p. 92; LIMA, R., 2007, p. 14). Entretanto, o documento não faz considerações a respeito do microclima ou amenização de ilhas de calor na cidade.

Localizada na Latitude de 22010' e Longitude de 47053', São Carlos têm na posição geográfica um dos fatores de maior significado na sua definição climática. Nesta latitude o movimento aparente do Sol resulta intensa insolação durante o ano todo e sua posição representa uma importante mudança no recebimento de energia solar na Terra. Sua área territorial é de $1.137,33 \mathrm{~km}^{2}$, sendo $67,25 \mathrm{~km}^{2}$ de área urbana, $6 \%$ da área total do município, onde residem 221,950 habitantes e tem uma densidade demográfica de 195,15 hab/km² (INSTITUTO BRASILEIR DE GEOGRAFIA E ESTATÍ́STICA, 2010) (Figura 4).

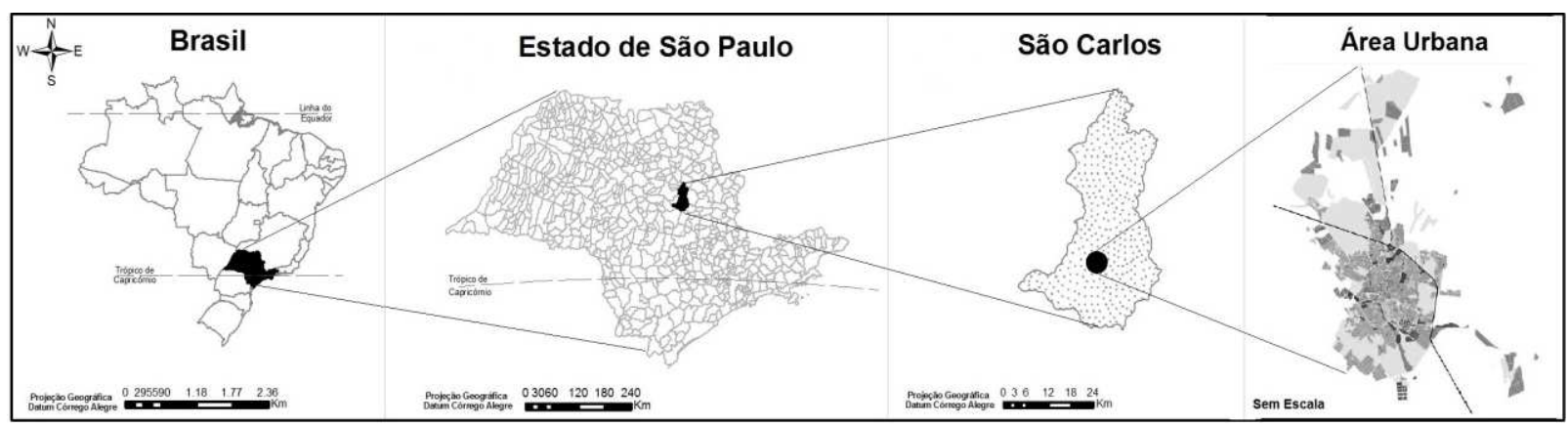

Figura 4: Localização das áreas de estudo. Fonte: Elaboração própria.

Segundo a classificação climática (MONTEIRO, C., 1973), São Carlos é qualificado como a região de climas controlados por massas equatoriais e tropicais, caracterizando-se por climas tropicais alternadamente secos e úmidos. No período seco a frequência de chuva diminui consideravelmente e se constitui na área de inverno mais nitidamente seco do Estado de São Paulo.

Os totais pluviométricos em São Carlos definem duas estações bem distintas, caracterizadas pelos seus totais pluviométricos: uma seca e outra chuvosa. A estação seca estende-se de Abril a Setembro, caracterizada por precipitações escassas. A estação chuvosa ocorre nos meses de Outubro a Março, devido às incursões da massa Equatorial Continental e ao dinamismo da Frente Polar Atlântica sobre a Tropical Atlântica, que responde em grande parte, pela gênese das chuvas que se produzem durante a atuação de sistemas frontais nesse período do ano (MONTEIRO, C., 1973; BARBOSA, R., 2009). 


\section{Materiais e Métodos}

A metodologia empregada neste estudo, foi dividida em três grandes grupos: instrumentação, métodos de observação e seleção de dias de medição.

Para o grupo da instrumentação e equipamentos, utilizou-se um termômetro digital infravermelho para aferição da temperatura superficial aparente fixado em um tripé de alumínio a 1,30m em uma cota aproximada da altura média dos indivíduos (INSTITUTO BRASILEIRO DE GEOGRAFIA E ESTATÍSTICA, 2009), que transitam pelos espaços livres da cidade, com a aferição manual dos setores cardeais e colaterais Norte (N), Nordeste (NE), Leste (L), Sudeste (SE), Sul (S), Sudoeste (SO), Oeste (O) e Noroeste (NO), para as angulações de -10 ㅇ e 0 ‥ Tais angulações buscaram fazer as leituras direcionadas para o chão, ou próximo dele, e a altura entre $1 \mathrm{~m}$ e 1,30m (Figura 5).

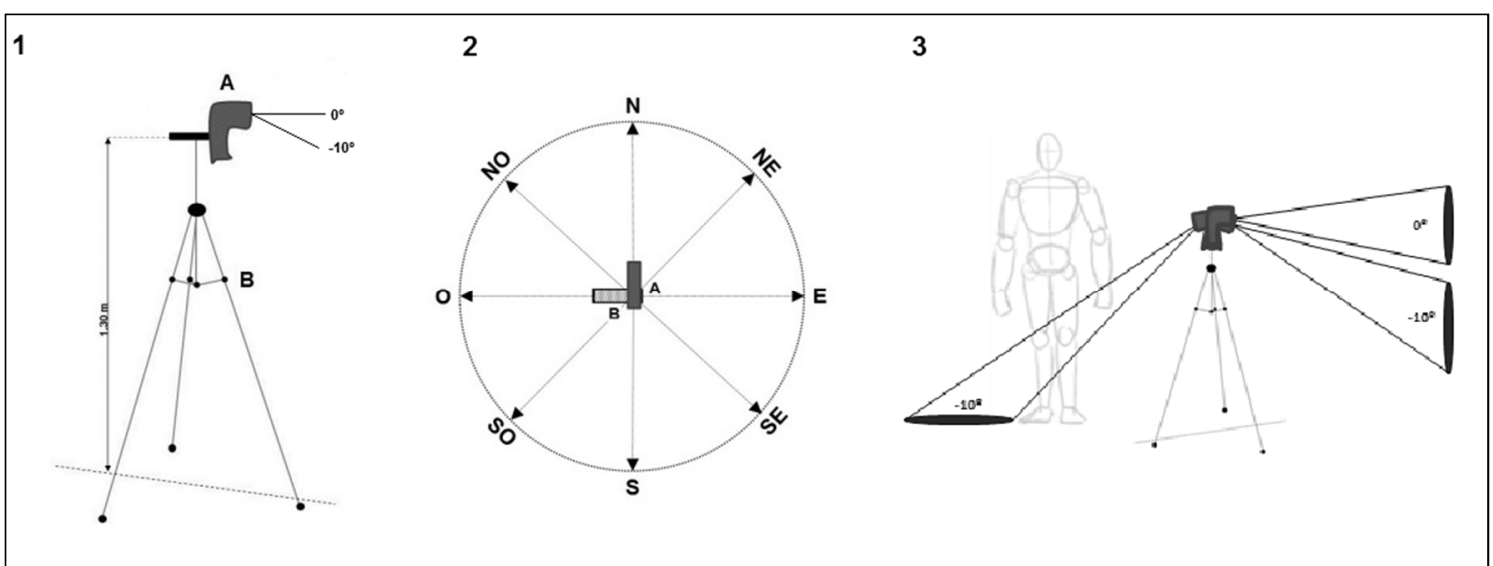

Figura 5: (1 e 3) Esquema dos ângulos de visada; (2): Posições cardeais e colaterais; (A): Termômetro digital infravermelho; (B): Tripé de alumínio. Fonte: Elaborado pelos autores.

Como método de observação, adotou-se as medidas horárias (ocorreram) entre às $9 \mathrm{~h}$ e $15 \mathrm{~h}$ a fim de evitar a interferência de sombreamento e possibilitar a maior incidência da energia solar, no período de inverno, estação do ano onde há pouca nebulosidade.

No tocante ao grupo de seleção de dias de medição, o dia experimental escolhido deveria sempre se aproximar o mais fielmente possível da insolação teórica plena, onde a radiação solar incide sobre todos os alvos, sem a interferência das nuvens, situação que ocorre frequentemente na estação de inverno nesta região de estudo. Desta forma, com saldo favorável de entrada de energia, ter-se-ia a certeza de que a radiação de onda longa emitida 
pelos objetos foi estimulada pela entrada de radiação de onda curta solar plena (NEVES, G. FELÍCIO, R. e MACEDO, S., 2015).

Os dados observados pelo termômetro infravermelho procederam da seguinte maneira: Um disparo curto no gatilho do termômetro para que o sensor seja previamente sensibilizado com a energia do novo alvo/objeto; Três disparos "padrão" (aproximadamente 0,5s com o gatilho pressionado), realizando a média entre os valores. Os três disparos garantiriam a ausência de erro e leitura tanto pelo sensor quanto pelo operador.

Os valores foram anotados em uma planilha de campo, digitados e organizados no Programa Microsoft Excel em ordem cronológica horária. Em todos os pontos amostrais foram realizados os registros fotográficos dos oito setores de visada por meio de uma câmera digital acoplada ao celular, pelo operador.

\subsection{Materiais utilizados}

Os materiais utilizados na presente pesquisa estão ordenados a seguir:

1 Termômetro Infravermelho Digital, Instruterm, modelo HM-6989;

1 Tripé de alumínio de 1,30m de altura, Targus;

Para a interpretação e o reconhecimento dos sistemas atmosféricos atuantes na região, foram adquiridas as imagens diárias do Satélite Geoestacionário GOES-13, Canal 4 do infravermelho (IR), disponibilizadas pela Divisão de Satélites Ambientais (DSA) do Centro de Previsão do Tempo e Estudos Climáticos do Brasil - Instituto Nacional de Pesquisas Espaciais (BRASIL-CPTEC-INPE), às 15h.

\section{Resultados e Discussão}

A seguir serão apresentados os experimentos de campo realizados em quatro tipologias urbanas representativas dos espaços livres quadra verticalizada, avenida São Carlos, distrito industrial e loteamento horizontal para a cidade de São Carlos-SP. 


\subsection{Espaços Livres Quadra Verticalizada (P1); Avenida São Carlos (P2); Distrito Industrital (P3); Loteamento Horizontal (P4).}

O experimento P1 foi realizado no dia 23 de Agosto de 2013. O ponto foi escolhido por apresentar um conjunto de massas edificadas superiores a oito pavimentos em uma distância de vinte e cinco metros em si, representando a rugosidade urbana no formato de cannyon ou "trincheira urbana". Os elementos edificados, arbóreos e os diferentes pavimentos como asfalto e calçada de concreto impermeabilizado foram outro aspecto potencial para a escolha do referido local de investigação.

O experimento P2 foi realizado no dia 02 de setembro de 2013. Ao longo da avenida, há uma crescente expansão dos edifícios verticais que se misturam com outras massas edificadas de menor porte e as residências térreas construídas em épocas pretéritas da cidade. Esses elementos se configuram no tecido urbano e dão o caráter de "espinha dorsal" à principal via de tráfego de automóveis da cidade de São Carlos.

O experimento P3 foi realizado no dia 06 de setembro de 2013. A vocação econômica da região é predominantemente comercial e de serviços industriais, com intenso tráfego de veículos de porte variado como carros, caminhões de carga e outros. O bairro é situado na região sudeste da cidade, sendo instituído em 1954 para atender a crescente demanda de loteamentos criados para a classe trabalhadora e as indústrias que começavam a instalar-se nas vias paralelas e perpendiculares à Avenida Getúlio Vargas.

O experimento P4 foi realizado no dia 08 de setembro de 2013. A região onde se situa o loteamento horizontal é ocupada por edificações térreas e alguns sobrados de dois pavimentos. O entorno do experimento de campo é pouco arborizado e as áreas permeabilizadas no interior dos lotes são escassas ou nulas. Possui um número significativo de parcelamentos espontâneos sendo implantado à margem da legislação e autorização da Prefeitura Municipal na década de 1970 (Figura 6). 


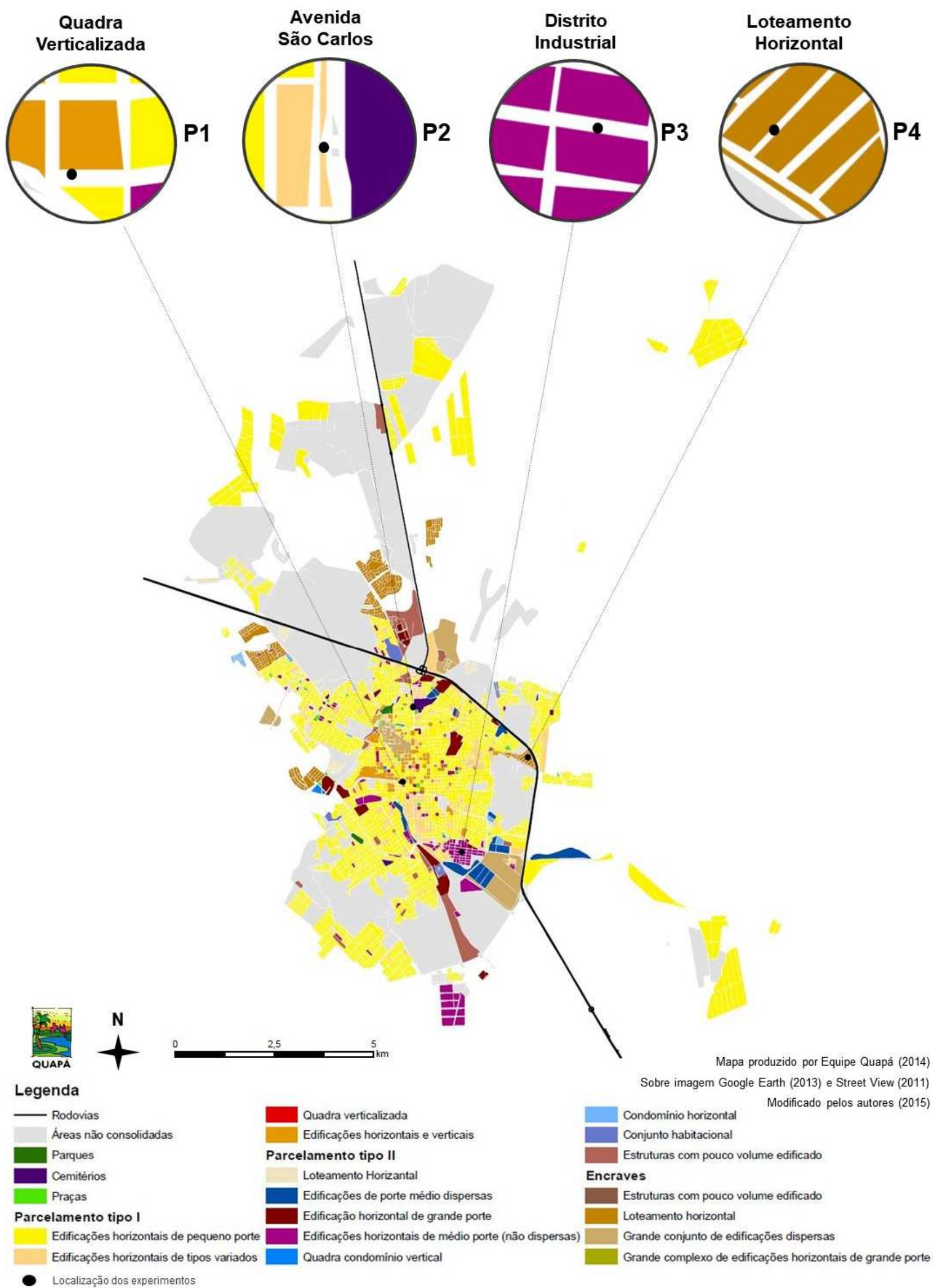

Figura 6: Parcelamento do solo e Volumetria Construída Intraquadra com destaque para as localidades dos experimentos de campo. Fonte: Equipe QUAPÁ-SEL (2014), modificado. 
A Figura 7 apresenta em gráficos do tipo radar as temperaturas de superfície aparente nos setores cardeais e colaterais, com a adição de registros fotográficos terrestres e um croqui transversal da área estudada. A imagem ilustra de forma individualizada a evolução da temperatura superficial das localidades supracitadas, sem intenção de compará-las entre si.

No início do experimento as linhas revelam um padrão próximo do centro do gráfico, demonstrando temperaturas modestas nos horários iniciais do experimento. Contudo, nos experimentos seguintes, principalmente na angulação -10 , as linhas se afastam do centro dos gráficos revelando o aumento das temperaturas devido à intensificação da radiação solar, porém sem uma orientação cardeal/colateral preferencial associada às áreas de sombra ou a ação direta dos raios solares das localidades de estudo.

P1
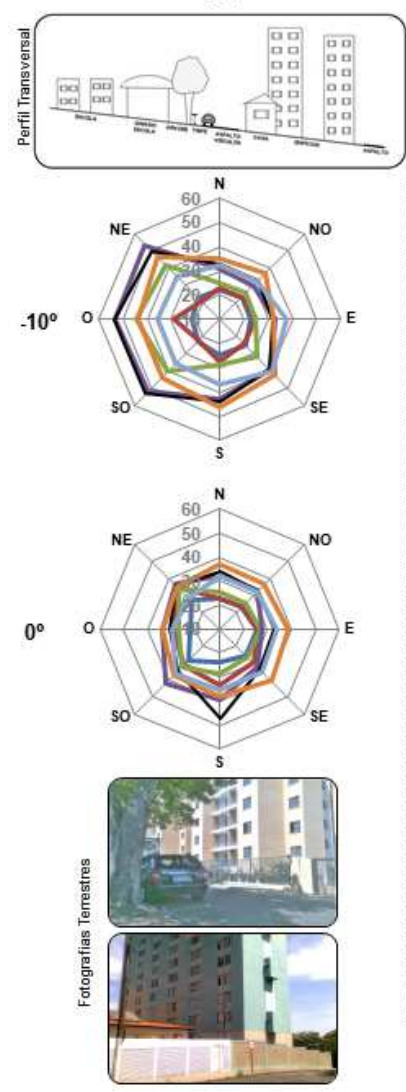

P2
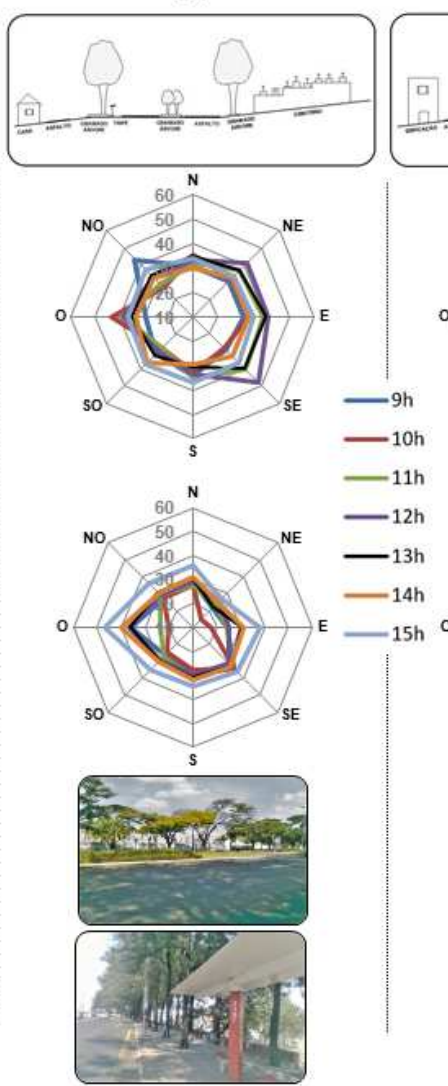

P3
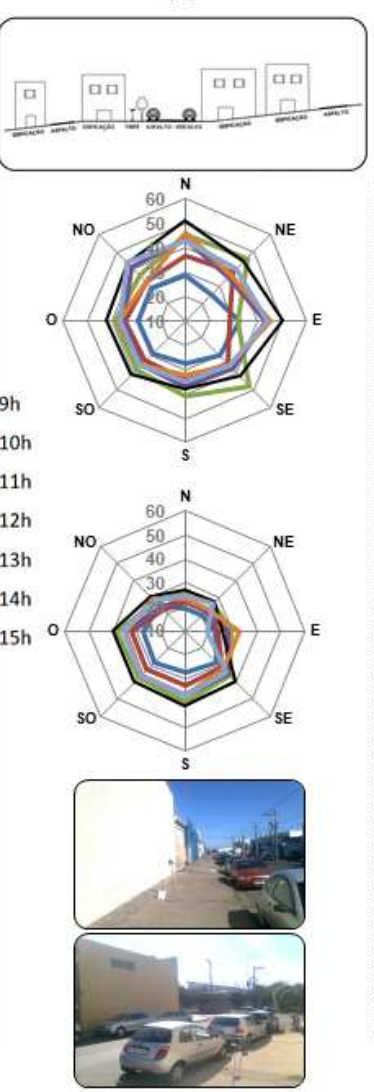

P4

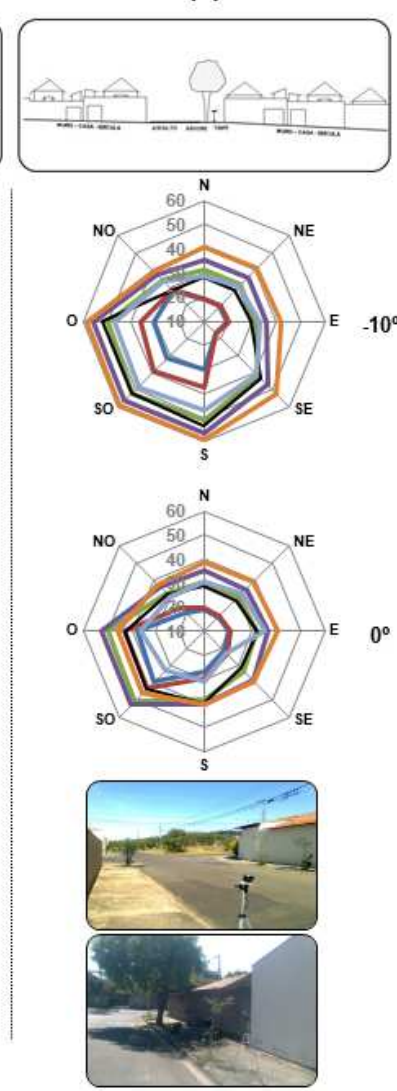

Figura 7: Evolução dos padrões térmicos apresentados nos quatro sítios urbanos analisados. Fonte: Elaborado pelos autores.

Observou-se que em todos os experimentos realizados o termômetro infravermelho, quando apontado para a angulação -10 , , registrou as temperaturas superficiais mais elevadas que a angulação apontada para o horizonte 0 ㅇ. 
Para o conjunto de elementos do experimento quadra verticalizada (P1), na angulação -10 ㄷ C as temperaturas superficiais foram próximas dos $44^{\circ} \mathrm{C}$ entre às $12 \mathrm{~h}$ e $14 \mathrm{~h}$, nos setores sul, sudoeste, oeste e noroeste, principalmente pela incidência direta dos raios solares nos pavimentos de calçadas de concreto e asfalto. Logo, para o ângulo 0으 as temperaturas superficiais foram ligeiramente inferiores com valores homogêneos entre $35^{\circ} \mathrm{C}$ e $38^{\circ} \mathrm{C}$ para os setores noroeste, leste, sudeste, sul e sodoeste. No período da manhã, os primeiros registros horários revelaram temperaturas ainda menores em decorrência do sombreamento provocado pelas edificações e a massa arbórea.

No experimento da avenida São Carlos (P2) os setores norte, nordeste, leste e sudeste apresentaram temperaturas de superfície elevadas, com valores entre $41^{\circ} \mathrm{C}$ e $44^{\circ} \mathrm{C}$ na angulação apontada para -10․ Os menores valores foram registrados no período da manhã, às $9 \mathrm{~h}$. $\mathrm{O}$ efeito do sombreamento das árvores de grande porte provocou um efeito de maior temperaturas para os setores sul, sodoeste e oeste na angulação 0‥ Com valores termais mais amenos, os registros não superaram $38^{\circ} \mathrm{C}$ nos horários de $11 \mathrm{~h}$ e $13 \mathrm{~h}$. Para os setores norte e nordeste as temperaturas foram sensivelmente reduzidas entre $23^{\circ} \mathrm{C}$ e $26^{\circ} \mathrm{C}$.

O terceiro experimento realizado no distrito industrial (P3) registrou as maiores temperaturas somando os horários medidos e setores, em ambas as angulações. Para os pavimentos asfálticos e calçadas de concreto, na angulação -10, nos setores SE, S, SO e O as temperaturas superficiais superaram os $44^{\circ} \mathrm{C}$ entre às $11 \mathrm{~h}$ e $15 \mathrm{~h}$. Na angulação sobrejacente 0 ㅇ, nos setores $\mathrm{SO}$ e $\mathrm{O}$, as temperaturas foram constantemente elevadas a $44{ }^{\circ} \mathrm{C}$, entre $10 \mathrm{~h}$ e 14h. As paredes dos elementos edificados e a baixa incidência de elementos arbóreos foram os principais condicionantes para as elevadas temperaturas de superfície.

No loteamento horizontal (P4) as temperaturas de superfície foram mais reduzidas que os experimentos anteriores, com valores termais de 44 으 $\mathrm{C}$ apenas para o setor SE às $12 \mathrm{~h}$. Outros setores revelaram temperaturas variadas de $17{ }^{\circ} \mathrm{C}$ e $32^{\circ} \mathrm{C}$. No ângulo 0 으 as temperaturas também foram reduzidas em todos os horários do experimento com valores mínimos entre 14 으 e 23 으.

A seguir, (Figura 8) os dados são exibidos em superfícies de contorno bidimensionais que unem dois conjuntos de dados numéricos. Os padrões de cores de superfície indicam áreas 
que contém o mesmo intervalo de valores. Na abcissa é apresentado o setor cardeal e colateral, e na ordenada, os horários das observações.
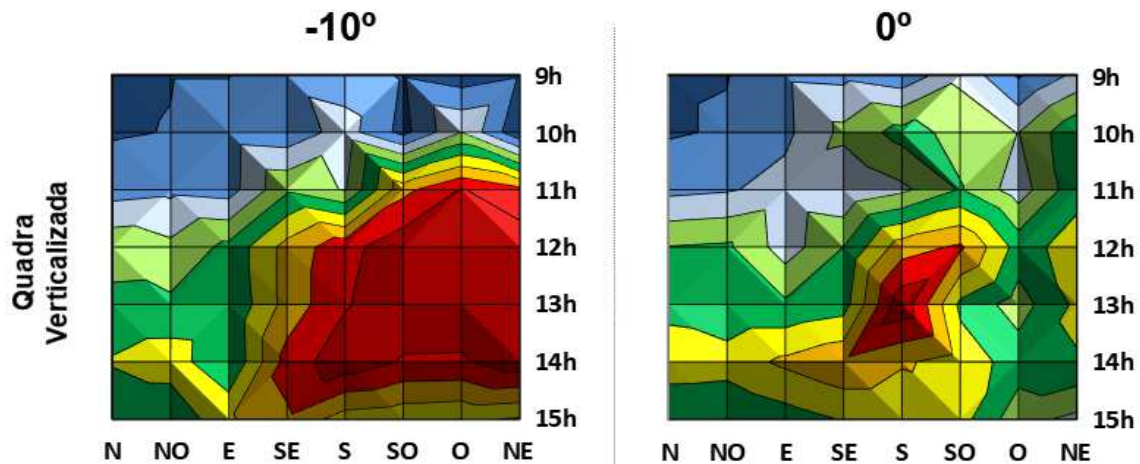

Legenda $\left({ }^{\circ} \mathrm{C}\right)$
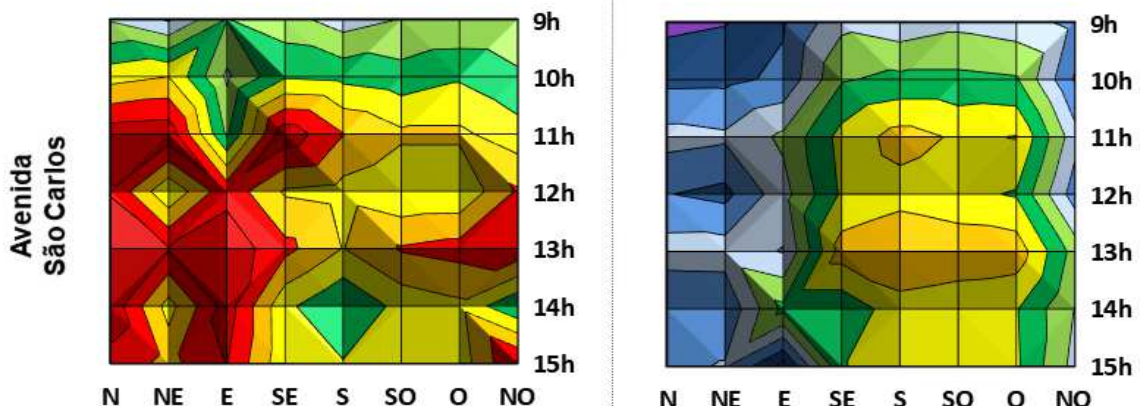

$\square$ 41-44

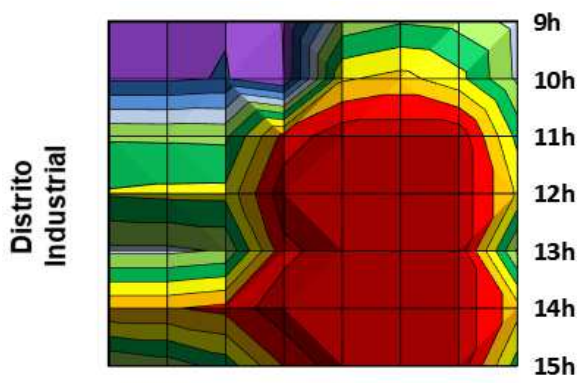

N NE E SE S SO O NO

\section{$\square 38-41$}

$\square$ 35-38

$\square 32-35$

$\square 29-32$

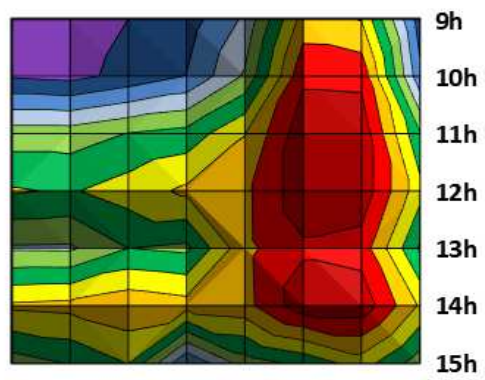

$\square 26-29$

$\square 23-26$

$\square 20-23$

$\square 17-20$

N NE E SE $S$ SO $O$ NO

N NE $\quad$ E $\quad$ SE $S$ SO $O$ NO
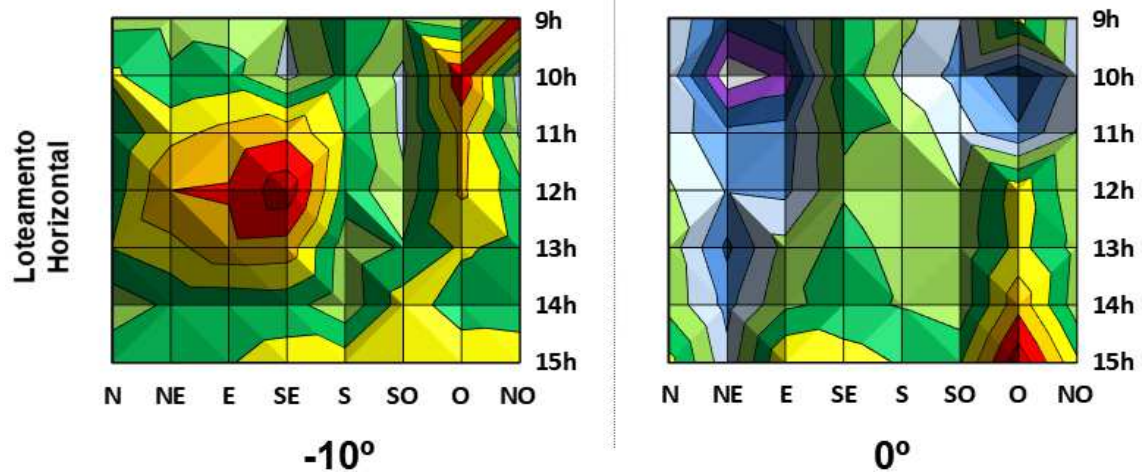

$\square$ 14-17

Figura 8: Evolução das temperaturas superficiais aparente nas angulações -10 e e 0 ㅇ no período de 22 de agosto, 02, 06 e 08 de setembro de 2013 para as quatro localidades estudadas (P1, P2, P3 e P4). Fonte: Dados obtidos nos experimentos de campo. Elaborado pelos autores. 


\subsection{Análise do mapa Parcelamento do Solo e Volumetria Construída Intraquadra de São}

\section{Carlos-SP.}

As quatro localidades foram classificadas seguindo os grupos principais do parcelamento das quadras, mencionadas pelo número correspondente aos experimentos de campo, a seguir:

Parcelamento do Tipo I - Experimento P1 e Experimento P2: 'Edificações horizontais e verticais' e 'Edificações horizontais de tipos variados'.

Parcelamento do Tipo II Experimento P3: 'Edificações horizontais de médio porte (não dispersas)';

Parcelamento do Tipo Encraves - Experimento P4: 'Loteamento horizontal'.

Parcelamento do Grupo I - Espaços Livres 'Quadra Verticalizada' (P1) é provido de árvores de portes variados e edificações de grande porte com mais de quinze pavimentos. 0 principal fator para que os valores termais tenham sido elevados em alguns setores justificase pela incidência direta da radiação solar em materiais como o concreto, asfalto e paredes de tijolos. O sombreamento provocado pela massa arbórea e edificada reduziu a temperatura superficiais em alguns setores no período da tarde.

Nos Espaços Livres da "Avenida São Carlos" (P2), a evolução termal durante o período de investigação apresentou amplitudes de temperaturas entre $25,0 \circ \mathrm{C}$ e $31,0 \circ \mathrm{C}$. A densa cobertura arbórea e o sombreamento imposto por esta não foram suficientes para reduzir as temperaturas obtidas nos setores investigados. Em todos os horários os valores termais foram superiores a 27,0 으 para o ângulo -10으, de superfícies variadas (calçada de concreto, asfalto, gramado e muro de tijolo), com sombreamento parcial ou total durante a maior parte do período investigado.

Parcelamento do Grupo II - Os Espaços Livres 'Distrito Industrial' (P3), apresentou os valores de temperatura de superfície mais expressivos entre os quatro experimentos. A estabilidade atmosférica provocada por uma massa tropical atlântica e a baixa nebulosidade para a região de São Carlos foram os fatores do tempo atmosférico que podem justificar as elevadas temperaturas. Secundariamente, os elementos urbanos impermeáveis e a baixa densidade de árvores de médio e grande porte são condicionantes em micro-escala que interferiram diretamente na incidência da radiação solar no referido experimento. 
Parcelamento do Tipo Encraves - No 'Loteamento horizontal' P4 observou-se o aumento das temperaturas ao longo do período analisado, revelando uma amplitude térmica de 20 ㅇ C entre a primeira e última aferição, entre os ângulos -10 e 0․ Contudo, os dados revelaram uma duração menor das temperaturas mais elevadas, fato registrado apenas para o horário das $12 \mathrm{~h}$ no setor sudeste. Este padrão térmico exposto para a localidade, na angulação 0으, pode ser atribuído às faces das paredes e muros das residências estarem dispostas a receber menos radiação solar ao longo do dia e terem poucos sombreamentos ou a obstrução parcial da luz solar. O padrão construtivo de cobertura impermeabilizada como os corredores externos e a substituição dos quintais e jardins por edículas nos fundos dos lotes são elementos que afetam diretamente as trocas de energia por calor sensível.

\subsection{Episódio climático representativo dos experimentos de campo}

Os dias 22 e 23 de agosto de 2013, na cidade de São Carlos, são caracterizados pela tropicalização da massa polar atlântica e com o predomínio do céu sem nuvens. Entre os dias 02 e 06 de setembro de 2013, a massa tropical atlântica domina a região do Estado de São Paulo com situação do tempo estável, com poucas nuvens sobre a região de São Carlos. No dia 08 de setembro de 2013, sem a interferência de nuvens, o episódio é marcado pela transição da massa polar atlântica em fase de tropicalização, com temperaturas do ar elevadas e reduzida umidade relativa do ar.

As fases pós-frontais de domínio e tropicalização da massa tropical atlântica caracterizam o episódio estudado como os dias típicos ideais a experimentação de campo, com ausência de nebulosidade e elevadas amplitudes térmicas do ar na região de São Carlos-SP.

A Figura 9 representa as imagens do Satélite GOES-13, nos dias 23 de agosto e 02,06 e 08 de setembro de 2013 e evidencia os diferentes episódios e padrões de nebulosidade para a região em destaque. 

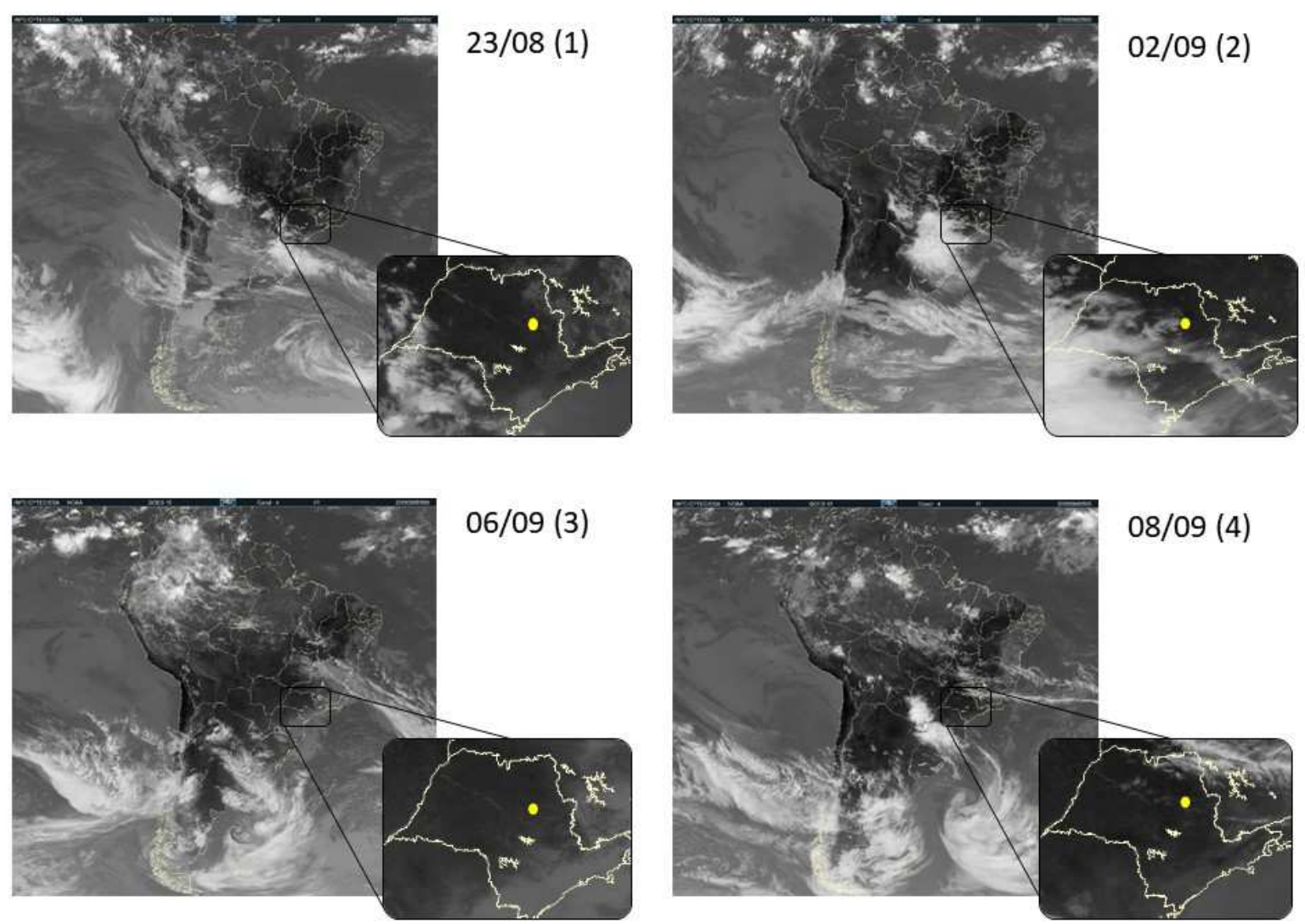

Figura 9: Imagem do Satélite GOES-13, Canal-4 IR dos dias 23 de agosto de 2013 e 02 , 06 e 08 de setembro de 2013 (1, 2, 3 4), às 15h, com destaque para o Estado de São Paulo e região São Carlos. Fonte: Centro de Previsão do Tempo e Estudos Climáticos - Instituto Nacional de Pesquisas Espaciais (2013), elaborado pelos autores.

\section{Considerações}

Na realização dos experimentos de campo observou-se que a temperatura de superfície variou nas fases de transição (domínio e tropicalização) da massa tropical atlântica. Fato demonstrado no episódio climático representativo dos experimentos de campo em diversos espaços livres, com o domínio polar impondo suas características genéticas, e nos dias seguintes, a massa polar apresentou características menos vigorosas em fase de tropicalização, elevando as temperaturas superficiais durante os experimentos.

As temperaturas mais elevadas foram registradas para as angulações -10 e e 0 ㅇ, quando o termômetro foi direcionado para as calçadas e asfaltos em que "há um fluxo radiativo 
emitido pelas superfícies urbanas e que amplitude térmica é maior na base destas estruturas, como paredes, ruas e calçadas" (MACHADO, A., 2009, p. 130).

Em uma primeira aproximação, podemos inferir que os valores de radiação solar interferem de modo distinto sobre as superfícies urbanas. Possivelmente, outros aparelhos como saldoradiômetros e pirgeômetros façam uma cobertura mais robusta na tentativa de corroborar com os valores de radiação solar obtidos na estação meteorológica.

Outra situação é o aumento das temperaturas ao ar entre os dias supracitados, principalmente na fase de tropicalização da massa de ar atuante. Notou-se que, pelos dados termais de superfície, os valores de temperatura do ar são consideravelmente inferiores que os de superfície. A temperatura do ar é menor em decorrência da presença de fluxos advectivos na camada de mistura intraurbana, que não aquece de maneira homogênea e não tem a mesma capacidade de armazenar calor que as superfícies urbanas.

Os arranjos dos espaços livres e edificados nas tipologias estudadas, com limitadas áreas verdes tendem a concentrar energia na forma de calor, sobretudo na ocorrência de sistemas atmosféricos menos vigorosos ou em fases evoluídas de tropicalização, exemplo ocorrido nos experimentos dos dias 23 de agosto e 06 de setembro de 2013.

Os espaços livres "Quadra Verticalizada" e "Distrito Industrial" (P1 e P4) possuem predisponência para a formação de ilhas de calor de superfície pela concentração do fluxo radiativo nos materiais edificados. O calor diurno é armazenado na massa dos elementos que compõem a envoltória das edificações. Quanto maior a massa térmica de um material, maior a sua capacidade de acumular calor.

Os padrões construtivos de cobertura impermeabilizada dos lotes e quadras como as calçadas de concreto e a substituição dos quintais e jardins por edículas nos fundos dos lotes são elementos que afetam diretamente as trocas de energia por calor sensível.

Todavia, sua validade está em considerar suas especificidades locais com a existência de inúmeros micro-climas em um mesmo bairro residencial e as possibilidades de arranjo dos espaços livres e edificados, sobretudo a rua e a calçada, pois são elementos da forma urbana e da mobilidade no cotidiano urbano e vida pública. 


\section{Referências bibliográficas}

BARBOSA, Ricardo Victor. Estudo do campo térmico urbano de São Carlos (SP): análise da intensidade da ilha de calor urbano em episódio climático de verão. Tese (Doutorado em Ciências da Engenharia Ambiental), Escola de Engenharia de São Carlos, Universidade de São Paulo, São Carlos, 2009.

BRASIL. Ministério da Ciência e Tecnologia CPTEC/INPE. - Imagens de Satélite, Cachoeira Paulista, Disponível em: http://www.cptec.inpe.br/satélite. Consultado no período de 28/08 a 31/08/2013.

BRASIL. Presidência da República. Parcelamento do Solo Urbano. Lei 6.766/79. Brasília, DF. [consultado em: 2013-04-01], Disponível na Word Wide Web: http://www.planalto.gov.br/ccivil 03/leis/L6766.htm.

CAMPOS, Ana Cecília. et al. Os espaços livres na constituição da forma urbana brasileira. Anais da Conferência Anual da Rede Portuguesa de Morfologia Urbana. 2013, PNUM, Coimbra, Portugal, p.264-267.

DEVESCOVI, Regina Campos. Urbanização e Acumulação. Um estudo sobre a cidade de São Carlos. 1985. Dissertação (Mestrado em Administração e Planejamento Urbano), Pós-Graduação EAESP, Fundação Getúlio Vargas, São Paulo, 1985.

DOZENA, Alessandro. São Carlos e seu desenvolvimento: contradições urbanas de um polo tecnológico. Dissertação (Mestrado em Geografia Humana), Faculdade de Filosofia, Letras e Ciências Humanas, Universidade de São Paulo, São Paulo, 2001.

FABBRO NETO, Francisco. Avaliação Ambiental Estratégica para Planos de Uso e Ocupação do Solo: um estudo sobre o Plano Diretor Municipal. Dissertação (Mestrado em Ciências da Engenharia Ambiental), Escola de Engenharia de São Carlos, Universidade de São Paulo, São Carlos, 2010.

FERRARI, Antônio. Variabilidade e tendência da temperatura e pluviosidade nos municípios de Pirassununga, Rio Claro, São Carlos e São Simão (SP): estudo sobre mudança climática de curto prazo em escala local. Tese (Doutorado em Ciências da Engenharia Ambiental), Escola de Engenharia de São Carlos, Universidade de São Paulo, São Carlos, 2012.

IBGE - INSTITUTO BRASILEIRO DE GEOGRAFIA E ESTATÍSTICA. Censo Demográfico 2010. [consultado em: 201311-02], Disponível na Word Wide Web: <http://cod.ibge.gov.br/H6Q>

IBGE - INSTITUTO BRASILEIRO DE GEOGRAFIA E ESTATÍSTICA. Antropometria e estado nutricional de crianças, adolescentes e adultos no Brasil (2009). [consultado em 2013-07-02]. Disponível na Word Wide Web: <http://www.ibge.gov.br/home/estatistica/populacao/condicaode vida/pof/2008 2009 enc aa/tabelas pdf/tab2 3.pdf>

LIMA, Renata. O processo e o (des)controle de expansão urbana de São Carlos (1857-1977). Dissertação (Mestrado em Arquitetura e Urbanismo), Escola de Engenharia de São Carlos, Universidade de São Paulo, São Carlos, 2007.

LEME, Iracy Os espaços livres de uso público no centro da cidade de São Paulo. Dissertação (Mestrado em Estruturas Ambientais Urbanas). Faculdade de Arquitetura e Urbanismo, Universidade de São Paulo, São Paulo, 2001.

MAGNOLI, Miranda Espaços livres e urbanização: uma introdução a aspectos da paisagem metropolitana. Tese (Livre-docência em Arquitetura e Urbanismo). Faculdade de Arquitetura e Urbanismo, Universidade de São Paulo, São Paulo, 1982.

MACEDO, Silvio. QUAPÁ-SEL - um projeto de pesquisa em rede. I Encontro Nacional de Pesquisa e PósGraduação em Arquitetura e Urbanismo (ENANPARQ). 15p. Rio de Janeiro, 2010, ISSN 2358-6214. (a)

MACEDO, Silvio. Os sistemas de Espaços livres e a constituição da esfera pública contemporânea no Brasil. Coleção QUAPÁ. 2010, São Paulo. (b)

MACEDO, Silvio. Lugares, espaços livres e contemporaneidade - características dos sistemas de espaços livres das cidades brasileiras contemporâneas. In: RHEINGANTZ, P. A.; PEDRO, R. Org. Qualidade do lugar e cultura contemporânea: controvérsias e ressonâncias em coletivos urbanos. Rio de Janeiro: Universidade Federal do Rio de Janeiro/FAU/PROARQ, 2012. pg. 145-152. 
MACEDO, Silvio. et al. Sistemas de espaços livres e forma urbana: algumas reflexões. In: XV ENANPUR Encontro Nacional da Associação Nacional de Pesquisa e Pós-Graduação em Planejamento Urbano e Regional, 2013, Recife. XV ENANPUR. Recife: ANPUR / UFPE, 2013. v. 1. p. 1-16, ISBN: 1981-7525.

MACHADO, Antônio. Distribuição espacial do fluxo radiativo em ondas longas na Região Metropolitana de São Paulo. Tese (Doutorado em Geografia Física), Programa de Pós-Graduação em Geografia Física, Faculdade de Filosofia, Letras e Ciências Humanas, Universidade de São Paulo, São Paulo, 2009.

MACHADO, Antônio. Fluxos radiativos da Avenida Paulista - São Paulo, SP - discutidos a partir da análise das formas. Caderno Prudentino de Geografia, Presidente Prudente, ago./dez.2011, n.33, v.2, p.21-41, ISSN 21765774.

MACHADO, Antonio. e AZEVEDO, Tarik. Spatial Distribution in long-wave radiation flux in São Paulo City, Brazil. World Journal of Engineering and physical Sciences, 2013, v. 1, p. 33-52, ISSN 2331-1878.

MARQUES, Emanuel. Tipologias ambientais para o adensamento urbano. Dissertação de Mestrado, Escola de Engenharia de São Carlos, Universidade de São Paulo, São Carlos, 1985.

MONTEIRO, Carlos Augusto. Frente Polar Atlântica e as Chuvas de Inverno na Fachada Sul-Oriental do Brasil (contribuição metodológica à análise rítmica dos tipos de tempo no Brasil). Série Teses e Monografias, 1 IGEOG/ USP, São Paulo, 1969. 69p.

MONTEIRO, Carlos Augusto. Análise rítmica em climatologia: Problemas da atualidade climática em São Paulo e achegas para um programa de trabalho. Climatologia n.1. São Paulo: IGEOG/USP, 1971. 21p.

MONTEIRO, Carlos Augusto. A dinâmica climática e as chuvas no Estado de São Paulo. Estudo geográfico sob a forma de Atlas. São Paulo: Instituto de Geografia da Universidade de São Paulo, 1973. 130p.

MONTEIRO Carlos Augusto e MENDONÇA, Francisco. (Org). Clima Urbano. São Paulo: Contexto, 2003, 192p., ISBN 8572442391.

NEVES, Gustavo.; FELICIO, Ricardo.; MACEDO, Silvio. Variação da temperatura de superfície na cota do pedestre na Avenida XV de Novembro, São Carlos-SP, Brasil. Revista de Morfologia Urbana - Rede Lusófona de Morfologia Urbana, 2015, v. 3, p. 31-40, ISSN 2182-7214.

NUNEZ, Manuel.; OKE, Timothy. The Energy Balance of an Urban Canyon. Journal of Applied Meteorology, 1977, 16, 11-19, http://dx.doi.org/10.1175/1520-0450(1977)016<0011:TEBOAU>2.0.CO;2

OKE, Timothy. Boundary layer climate. London: Methuen \& CO. 1978, 460p., ISBN 0-415-04319.

PREFEITURA MUNICIPAL DE SÃO CARLOS. Conferência Municipal da Cidade - PMSC, 2003, CD-ROOM.

PREFEITURA MUNICIPAL DE SÃO CARLOS. Lei Municipal 13.691 de 2005. Plano Diretor do Município.

RIBEIRO, Antônio. As Escalas do Clima. Boletim de Geografia Teorética, 1993, 23 (46-46): 288-294, ISBN 0109761.

STEWART, lain. and OKE, Timothy. 2012. T. R. Local climate zones for urban temperature studies. American Meteorological Society, 2012,93 (12), p. 1879, http://dx.doi.org/10.1175/BAMS-D-11-00019.1

VECCHIA, Francisco. Clima e ambiente construído: a abordagem dinâmica aplicada ao conforto humano. Tese (Doutorado em Geografia Física), Programa de Pós-Graduação em Geografia Física, Faculdade de Filosofia, Letras e Ciências Humanas, Universidade de São Paulo, São Paulo, 1997.

VOOGT, James and OKE, Timothy. Complete Urban Surface Temperatures. Journal of Applied Meteorology, 1997, 36, p. 1117 - 1132, http://dx.doi.org/10.1175/1520-0450(1997)036<1117:CUST>2.0.CO;2 